\title{
Solar Trap for Banana Drying Method
}

\author{
S. Musa ${ }^{1, *}, I$. Ibrahim $^{2}, A . S$. Mohd $^{1}, M . M$. Shahabuddin $^{1}$ and $S$. Sulaiman $^{3}$ \\ ${ }^{1}$ Faculty of Civil and Environmental Engineering, Universiti Tun Hussien Onn Malaysia,86400, Batu \\ Pahat, Johor, Malaysia \\ ${ }^{2}$ Faculty of Engineering Technology, Universiti Tun Hussien Onn Malaysia,86400, Batu Pahat, Johor, \\ Malaysia \\ ${ }^{3}$ Jabatan Kerja Raya Kluang, 86000 Kluang, Johor, Malaysia
}

\begin{abstract}
Food drying methods nowadays are mostly in high use of electricity and fuel which lead to high operational cost. This has resulted in a waste of energy and money due to the use of modern tools requires significant costs for implementation. Meanwhile, the traditional food drying process only uses sun rays in their process, where the process is far more efficient than the modern drying method. In this study, the test was conducted to determine the trapped solar heat energy requirements for the process of drying foods such as agricultural products, particularly bananas. The solar trap test by using solar trap container was carried out include determining the thermal energy requirement for drying, preparing equipment (solar trap container) to trap solar energy, handling and drying tests on samples of bananas. The percentage amount of water removal and energy required for the drying process was found to be $48 \%$ and $134 \mathrm{~J}$. The results of this study can determine that solar trap drying method is easier, quicker and more effective than the usual method of drying because it use natural solar energy. Several proposals have been suggested for improvement for future study, such as controlling the solar trap air in the container, replacing the trap solar wall with a darker color, examining the floors slope so that more solar traps collected and installing a small hose on the base of the container so that the water evaporated in the solar trap may exit through the route.
\end{abstract}

\section{Introduction}

Solar energy is a technology to obtain useful energy from sunlight. Solar energy has been used in many traditional technologies for centuries and has been widely used in the absence of other energy supplies such as in remote areas and in space. Solar energy is now used in several applications such as hot water heating, heating of buildings and food. It is also used for electricity generation like fotovolik, engine heating and desalination of sea water. Its use becomes famous when awareness of the environmental costs and limited supplies of other energy sources such as fossil fuels become more pronounced [1].

\footnotetext{
*Corresponding author: sabariah@uthm.edu.my
} 
Solar energy is very important to our daily lives. The use of solar energy can also save electricity consumption especially when other resources are lacking or absent. Therefore, various methods have been developed to expand the use of solar energy, especially in the method of drying ood and agricultural products. Among them is the decisive requirement of thermal energy for drying. Then, setting up equipment to trap solar energy, operating and carrying out tests and taking measurements of the drying removal of water in the food and amount of energy required [2].

Parit Raja, Batu Pahat, Johor is a very famous village as a result of making dried banana which only uses sunlight as a means of drying. This study is to identify the quantity of solar energy derived from the sun and collected in an air tight confine vessel that are used for drying of agricultural products. This study was conducted to test the effectiveness of using solar traps drying method than the usual drying methods without the use of solar trapping. The scope of this study is to determine the thermal energy needed for drying purposes, preparing for solar trapping equipment, conducting and testing solar traps and also measuring the removal of water from the food and energy needs.

\section{Related Studies}

Based on study [3], it found that evaporation is the conversion of water from liquid to gas. About $80 \%$ of all evaporation is from the ocean, with the remaining $20 \%$ coming from inland water and vegetation. Wind carries evaporated water over the world, affecting air humidity around the world.

However, heat (energy) is necessary for evaporation to occur. Energy is used to break the bonds that hold water molecules together, which is why water easily evaporates at the boiling point of $\left(212^{\circ} \mathrm{F}, 100^{\circ} \mathrm{C}\right)$ but evaporates more slowly at the freezing point. Net evaporation occurs when the rate of evaporation exceeds the rate of condensation. Saturation exists when these two processes rates are equal, at which point the relative humidity is $100 \%$. Condensation, the opposite of evaporation, occurs when saturated air is cooled below the dew point (the temperature at which air must be cooled at constant pressure to become fully saturated with water), such as the outside of a glass of ice water. In fact, the process of evaporation removes heat from the environment, which causes water to evaporate from your skin and becomes cool [4].

However, the drying process is divided into three categories: the imposition of air and air under atmospheric pressure, vacuum drying and freeze drying. In the air and the imposition of air under atmospheric pressure, the heat is transferred from the food through the hot air from hot or dry surfaces. Water vapour is removed through the air. In the vacuum drying, the evaporation of water occurs more easily at lower pressure compared when the pressure is higher. Heat transfer in vacuum drying generally occurs by conduction, sometimes through radiation. During freeze-drying, water vapour sublimed from the frozen food. Food structure is better maintained in this condition. Suitable temperature and pressure must be established in the dryer to ensure that the sublimation is accepted [5].

\section{Materials and Methods}

\subsection{Determining thermal heat requirements for drying purpose}

Determination of thermal energy is required for drying food stuffs and agricultural products to ensure that the energy require disappropriate and sufficient. The study of solar energy resources has been conducted and it was found that Malaysia is a country that receives 
sunshine in a very long period of over 10 hours a day. In addition, the study of materials that was used to create a heat trap in the container.

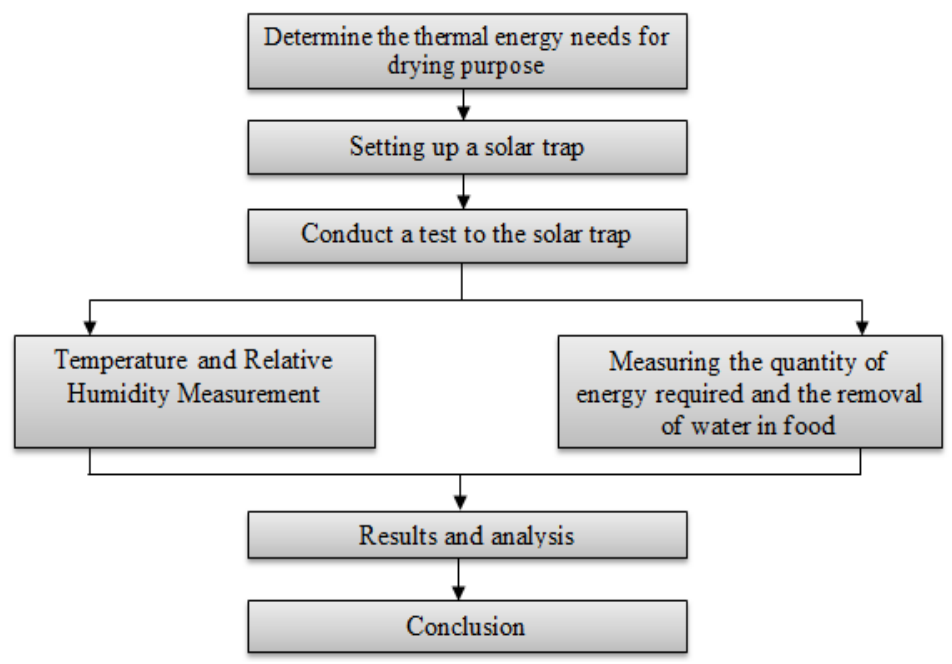

Fig. 1. Flow of banana drying process

\subsection{Setting up a solar trap}

A solar trap container as shown in Fig. 2 was prepared after a study was carried out to determine the thermal energy needs by using thermometer investigation. A container with the size of $2250 \mathrm{~cm}^{3}$ heat trap was created for drying food stuffs and agricultural products. Among the features found on the solar trap are:

1. The surface of the transparent glass on the upper surface of the solar trap.

2. Insulation white polystyrene containers found in solar panels on each wall of the solar trap.

3. The surface of the solar trap coated with a layer of black water translucent paper.

4. There is a thermometer on the mirror surface on the inside of the solar trap.

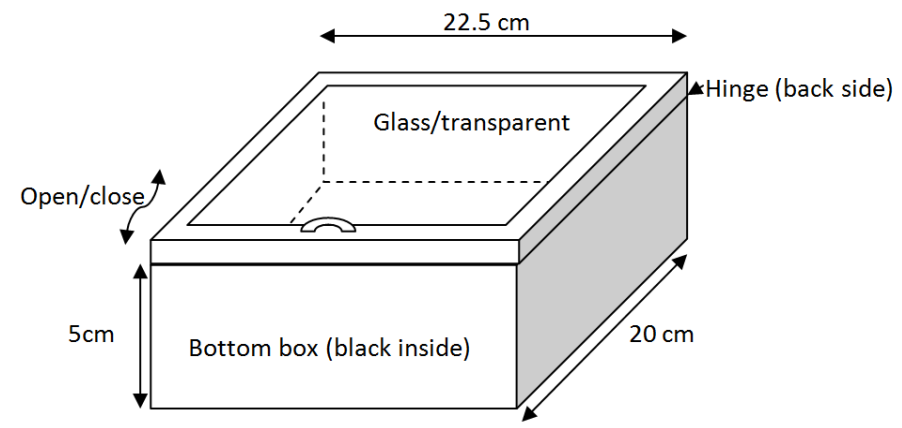

Fig. 2. Solar trap container for banana drying 


\subsection{Conducting solar trap testing}

The operation and testing of solar trap was performed after the completion of the solar trap container. This study was conducted approximately in less than two months to measure temperature, relative humidity, the amount of energy required and also the removal of water in food depending on weather conditions in the surrounding area. This study should be done during the day as at night there is no sunlight.

\subsection{Temperature and relative humidity measurement}

Measurement of the level of relative humidity in solartrap container was done manually by taking the wet bulb and dry bulb temperature data every one hour using a thermometer. The study was conducted for a week depending on weather conditions. Meanwhile, the solartrap container is placed in open spaces necessarily far from the shadow of trees or buildings thatcan block sunlight from penetrating the solar trap container. This study was conducted to determine that the temperature and relative humidity in the solar trap is not influenced by ambient temperature. This comparison was done to prove that the temperature in the solar trap is higher than the ambient temperature as well as more effective for drying foods such as dried bananas.

\subsection{Measurement quantity of energy required and water removal in food}

Measurement of water removal in food and the energy needed was carried out during the testing of the solar trap. This measurement is done by collecting data in the solar trap to examine the quantity of solar energy from the sun that can be collected by a solar trap container for drying agricultural products purpose.

Energy measurement is also carried out by using ordinary measuring temperatures by taking into account the initial temperature and the temperature after drying for a day was applied to food stuffs. Meanwhile, water removal measurement was done with regard to the original quantity of water and quantity of water after the drying process on food stuffs using a syringe or weighing machine.

Water removal is done by collecting data of the specimen's dryness to test the dryness rate in solartrap. Then, the specimen was replaced with food such as bananas after the dryness test was successful. Next, the solar trap drying method is compared to the usual method without solar trap drying.

\section{Results}

\subsection{Relative humidity and temperature in solar trap}

Data of dry bulb temperature and relative humidity in the solar trap that has been recorded and analyzed based on the relationship for both parameters. The process has the potential to dry foods such as bananas as shown in Fig. 3. This method is intended to ensure that the relative humidity affect the temperature of the solar trap to prove the effectiveness of the drying process. If relative humidity is lower, the temperature is higher because of expansion process. The Equation 1 was generated as

$$
R H s=103.02-0.0017 T s^{2}-0.6808 T s
$$


where;

RHs = Relative humidity of solar trap (\%)

$\mathrm{Ts}=$ Temparature of solartrap $\left({ }^{\circ} \mathrm{C}\right)$

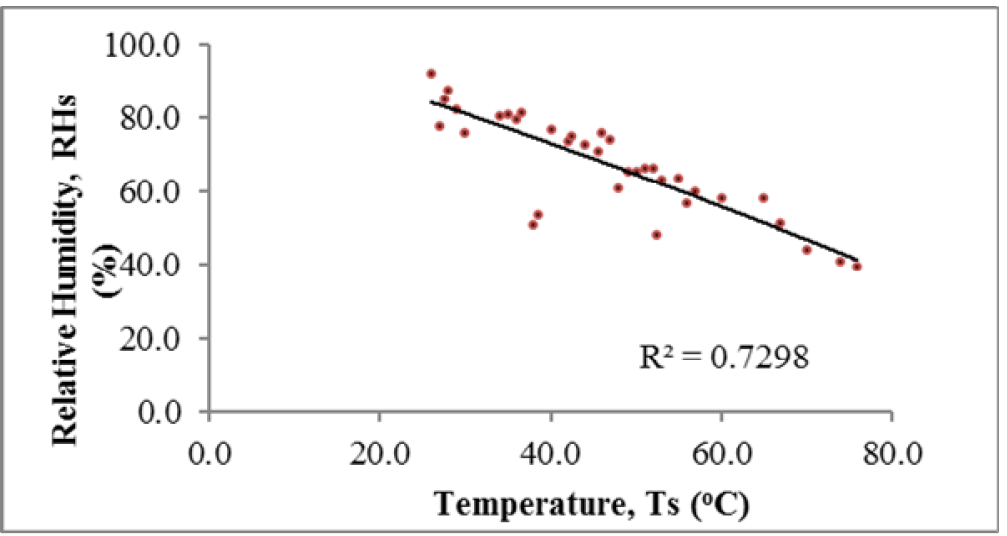

Fig. 3. Humidity and temperature in solartrap

\subsection{Relative humidity solar trap and ambient}

Fig. 4 shows the percentage of relative humidity of solar trap and ambient relative humidity more clearly. Ambient relative humidity percentages recorded the highest results compared to solartrap. This provesthat the former solar trap has a higherpotential and is very suitable for drying foods such as bananas than the usual drying methods due to being independent from the surrounding area.

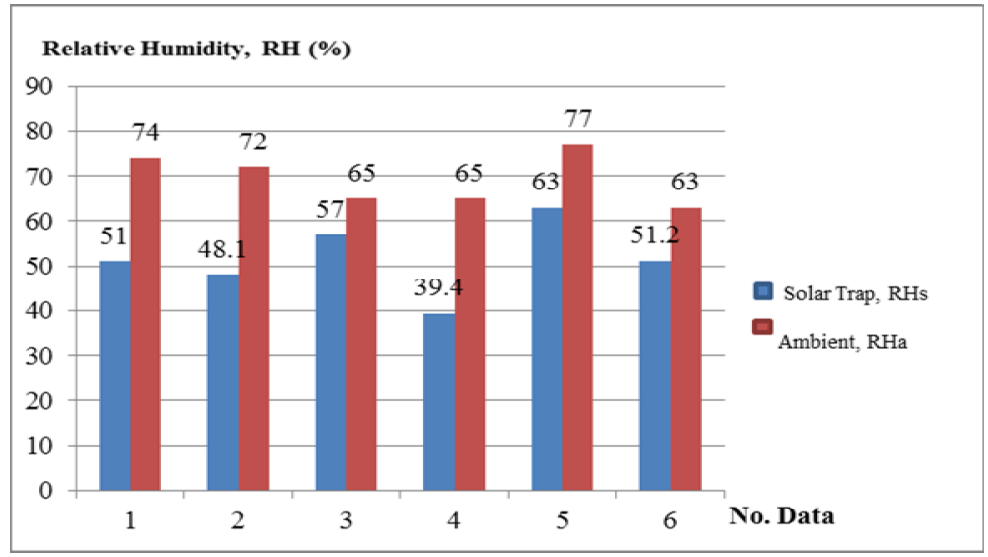

Fig. 4. Percentage reduction of relative humidity between solar trap and ambient

\subsection{Temperature between solar trap and ambient}

The variations in the temperature between the ambient and solar trap was shown in Fig. 5. This comparison was done to prove that the temperature in the solar trap is higher than the ambient temperature as well as more effective for drying foods such as dried bananas. This is due to several factor including ambient temperature of hot and cold air, the relative 
humidity was variable, wind speed and angle of sunlight either it is protected or unprotected. The relationship for each others was produced as Equation 2.

$$
T s=3.4282 T a-53.611
$$

where;

Ts $=$ Solar trap temperature $\left({ }^{\circ} \mathrm{C}\right)$

$\mathrm{Ta}=$ Ambient Temperature $\left({ }^{\circ} \mathrm{C}\right)$

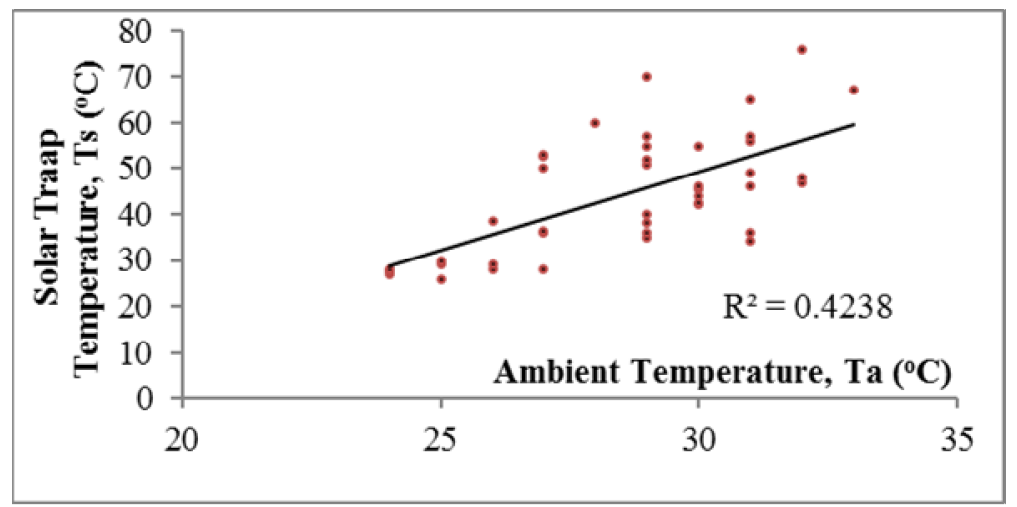

Fig. 5. Variation temperature in solar trap and ambient

\subsection{Energy required in solar trap}

The highest value for the average solar energy trapped in the solar trap is $31015.1 \mathrm{~J} / \mathrm{m}^{3}$, while the maximum energy that is trapped by solar traps was $49019.4 \mathrm{~J} / \mathrm{m}^{3}$. The average temperature change was considered was $16^{\circ} \mathrm{C}$. This is due to weather conditions in Malaysia that are erratic and the temperature conditions are constantly changing according to the surrounding area. In conclusion, the average energy trapped in the trap solar is high and enough to dry foods such as dried bananas only one day. Table 1 shows the average energy trapped in the solar trap.

Table 1.Average energy trapped in solar trap

\begin{tabular}{|c|c|c|c|c|c|c|c|}
\hline Date & 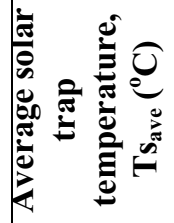 & 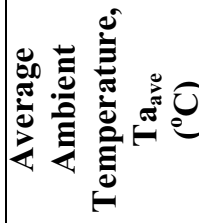 & 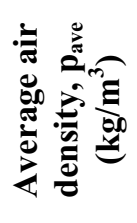 & 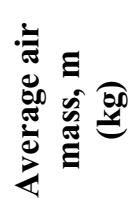 & 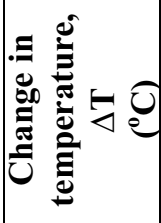 & 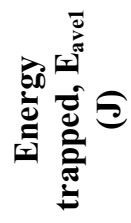 & 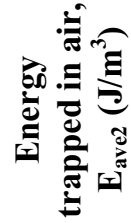 \\
\hline $19 / 3 / 2015$ & 36 & 30 & 1.106 & 0.0025 & 6 & 15.5 & 6907.3 \\
\hline $1 / 4 / 2015$ & 38 & 28 & 1.106 & 0.0025 & 11 & 26.9 & 11976.3 \\
\hline $2 / 4 / 2015$ & 45 & 28 & 1.106 & 0.0025 & 18 & 44.5 & 19774.9 \\
\hline $3 / 4 / 2015$ & 44 & 29 & 1.106 & 0.0025 & 15 & 37.1 & 16472.4 \\
\hline $4 / 4 / 2015$ & 56 & 28 & 1.106 & 0.0025 & 28 & 69.8 & 31015.1 \\
\hline $5 / 4 / 2015$ & 41 & 27 & 1.106 & 0.0025 & 14 & 35.1 & 15597.1 \\
\hline $6 / 4 / 2015$ & 48 & 30 & 1.106 & 0.0025 & 18 & 45.0 & 19983.8 \\
\hline
\end{tabular}




\subsection{Dryness process}

One dried banana only needs $134 \mathrm{~J}$ energy of drying process for 9 hours a day. While the average solar energy trapped in the trap is $31015.1 \mathrm{~J} / \mathrm{m}^{3}$. Approximately 200 to 300 bananas can be dried within one day compared to the normal drying, which takes three days at least. The data comparison between the sample and bananas are that bananas require lower energy and water removal rate for the drying process compared to the samples used within a day (Table 2). Therefore, the process of assessing the quantity of energy from the sun collected in a container for solar traps drying of agricultural products such as dried bananas had been achieved.

Table 2. Comparison between sample and banana

\begin{tabular}{|l|c|c|}
\hline \multicolumn{1}{|c|}{ Comparison } & Sample & Banana \\
\hline Rate of water removal, $\mathrm{MC}(\%)$ & 60 & 48 \\
\hline Quantity of water removed $(\mathrm{ml})$ & 3.0 & 2.5 \\
\hline Mass of water removed, $\mathrm{m}(\mathrm{kg})$ & 0.003 & 0.0035 \\
\hline Specific heat capacity, $\mathrm{C}_{\mathrm{p}}\left(\mathrm{KJ} / \mathrm{kg}^{\circ} \mathrm{C}\right)$ & 4.179 & 3.35 \\
\hline Energy required, E (J) & 201 & 134 \\
\hline
\end{tabular}

\section{Conclusion}

Based on the study that was conducted, dried banana needs only $134 \mathrm{~J}$ energy and drying process for 8 to 10 hours a day, while the average solar energy trapped in the solar trap is $31015.1 \mathrm{~J} / \mathrm{m}^{3}$. Therefore, the energy accumulated in the solar trap is sufficient to dry the banana. It can be estimated that about 200 to 300 bananas can be dried within one day compared to the usual drying methods which consume at least three days for the drying process.

This proves that the solar trap drying method is time, costs and energy efficient compared to drying methods without solar trap. It caused by the drying time and characteristics a drying place of foodstuffs. If bananas can be dried in large quantities in only one day, then this saves cost and time while using energy more efficiently and increasing banana production by $300 \%$.

In conclusion, this study can provide convenience to the surrounding communities to perform an easier, faster and more effective method of drying food. In addition, drying using solar trap is able to maintain the quality of bananas from insect and animal intrusion because food are typically exposed to the environment during the drying process without the use of solar traps.

\section{References}

[1] S. Zekai, Solar energy fundamentals and modeling techniques solar energy devices and collectors, Springer, 239-252 (2008)

[2] P.K. Jauhri, Sumber tenaga suria, Encyclopaedia of resource geography, Anmol Publications PVT. LTD, New Delhi, (2005)

[3] Department of atmospheric sciences (DAS), Urbana champaign, University of Illinoi, (2010)

[4] H. Perlman, The world's water, (2014), Retrieved on Mar 6, 2014 from http://water.usgs.gov/edu/earthwherewater.html 
[5] R. L. Earle and M. D. Earle, Drying, Unit operation in food processing, Chap. 7, The New Zealand institute of food science and technology Inc. (NZIFST), (1983) 